NBER WORKING PAPER SERIES

\title{
THE ROLE OF PATENTS FOR BRIDGING THE SCIENCE TO MARKET GAP
}

\author{
Thomas Hellman \\ Working Paper 11460 \\ http://www.nber.org/papers/w11460
NATIONAL BUREAU OF ECONOMIC RESEARCH 1050 Massachusetts Avenue
Cambridge, MA 02138
June 2005

This paper is part of the NBER special program on Academic Science and Entrepreneurship. I would like to thank the organizers, Adam Jaffe, Josh Lerner, Scott Stern and Marie Thursby, as well as Nancy Gallini, Ralph Winter, and seminar participants at the NBER workshop (Boston, 2004), the NBER Conference (Santa $\mathrm{Fe}, 2005$ ), the University of British Columbia (Vancouver), and the University of Victoria for their helpful comments. All errors are mine. Hellmann: 2053 Main Mall, Vancouver, B.C., V6T 1Z2. Tel: (604) 822 8476. Fax: (604) 822 8477. Email:hellmann@sauder.ubc.ca. The latest version of this paper can be downloaded from the website:http://strategy.sauder.ubc.ca/hellmann. The views expressed herein are those of the author(s) and do not necessarily reflect the views of the National Bureau of Economic Research.

(C)2005 by Thomas Hellmann. All rights reserved. Short sections of text, not to exceed two paragraphs, may be quoted without explicit permission provided that full credit, including (C) notice, is given to the source. 
The Role of Patents for Bridging the Science to Market Gap

Thomas Hellmann

NBER Working Paper No. 11460

June 2005

JEL No. O33, O34, M13

\section{ABSTRACT}

This paper examines an ex-post rationale for the patenting of scientific discoveries. In this model, scientist do not know which firms can make use of their discoveries, and firms do not know which scientific discoveries might be useful to them. To bridge this gap, either or both sides need to engage in costly search activities. Patents determine the appropriability of scientific discoveries, which affects the scientists. and firms. willingness to engage in search. Patents decrease dissemination when the search intensity of firms is sufficiently elastic, relative to that of scientists. The model also examines the role of universities. Patents facilitate the delegation of search activities to the universities' technology transfer offices, which enables efficient specialization. Rather than distracting scientists from doing research, patenting may be a complement to doing research.

Thomas Hellmann

Sauder School of Business

University of British Columbia

2053 Main Mall

Vancouver, BC V6T 1Z1

CANADA

thomas.hellmann@sauder.ubc.ca 


\section{Introduction}

Over the last few decades, the number of patents filed by university scientists has increased dramatically. In the US, an important driver for this has been the Bayh-Dole act. ${ }^{1}$ Given the central role that science plays in the development of new technologies, it is important to ask what effect the patenting of scientific discoveries is likely to have.

Standard economic theory emphasizes the incentive effects of patents. In order to be willing to invest in research and development, it is necessary to have a guarantee that the intellectual property generated by the investment is adequately protected against appropriation. A large theoretical literature has closely studied this rationale (Gallini and Scotchmer, 2001). The empirical evidence is sometimes inconclusive, but provides at least some support for an incentive effect of patents (Arora, Ceccagnoli and Cohen, 2003, Cohen et. al. 2002, Levin et. al., 1987). While the incentive rationale is reasonably persuasive for private sector $\mathrm{R} \& \mathrm{D}$, its applicability to academic research is more questionable: scientists did research long before patents existed; scientists are often intrinsically motivated (Murdock, 2002, Stern 2004) and concerned about academic freedom (Aghion, Dewatripont and Stein, 2005); and scientists' incentives are strongly affected alternative incentive systems, such as tenure (Carmichael, 1988). The effect of patents on scientists' effort to engage in research are likely to be small. If anything, the argument has been made that patenting can become a distraction to scientists: they may divert research from basic to applied fields, and they may tempt scientists to pursue private profits opportunities, through start-ups or industry collaborations (Shane (2004a), Thursby, Thursby and Mukherjee (2005)).

Apart from the ex-ante incentive argument, a small number of economists have argued that patents also play an ex-post role. Kitch (1977) argues that patents encourage the dissemination of scientific knowledge, after the discovery has already been made. See also Denicolò and Franzoni (2004). One important aspect is that there is a long path from scientific discovery to marketable new product. ${ }^{2}$ The scientific discovery is only one of several inputs in a risky development process, that hopefully leads to the eventual introduction a new product.

\footnotetext{
${ }^{1}$ See Henderson, Jaffee and Trajtenberg (1998), Jaffee (2000), Jaffee and Lerner (2001), or Gallini (2002).

${ }^{2}$ Our discussion here will focus mostly on product patents, although the argument is similar for process patents.
} 
If scientific discoveries are merely intermediate products, we have to distinguish two distinct scenario. In one scenario the final product is not patentable, nor can it be protected by other means, such as complementary assets or secrecy. In this case it is easy to see that patents for scientific discoveries are valuable. They solve the appropriability problem at the input level, when it cannot be solved at the final product level. Naturally, one has to ask why it is that only inputs but not outputs can be patented. We focus on the other scenario where the final product can be patented, or protected by other means. In this case, allowing patents for scientific discoveries allocates the intellectual property to the scientists, while allowing only patents on final products allocates the intellectual property to the firms that develop them. Under the Coase theorem, different allocations of intellectual property affect the distribution of rents, but not the outcome or efficiency of the development process. Naturally, the Coase theorem assumes efficient contracting. If all that is required is that a specific scientist and a specific firm agree on the terms of a development contract, then the Coase theorem seems appropriate.

In this paper we identify a fundamental problem that prevents efficient Coasian contracting. Scientists often do not know what the potential uses of their scientific discoveries are, nor do they know what firms may be potentially interested. Similarly, firms are often unaware of what scientific discoveries may be valuable for them. This is what we call the gap between science and the market. The process of commercialization has (at least) two important stages: there is the development stage, where the scientist and the firm need to combine their knowledge and assets to attempt commercial development. At this stage, efficient contracting may be possible. Prior to the development stage, however, there is a search stage, where a match has to be made between a scientific discovery and a firm that can potentially make use of it. Elfenbein (2005) shows that considerable time and effort are required to identify firms that are willing to license intellectual property from universities. At this search stage, there cannot be efficient contracting between the scientist and the firm, simply because they have not met yet. Hence the Coase theorem does not apply, and the allocation of intellectual property rights matters. This is the starting point of our analysis concerning an ex-post rationale for patenting scientific discoveries.

A typical economic argument might go as follows. Consider a scientist who has made a discovery that no one knows about. The scientist can invest some time and money into promoting her discovery, searching for an appropriate firm that can use 
it for the development of some new product. Without patent protection, when the scientist discloses the discovery to the firm, the firm can appropriate the discovery. This ruins the scientist's incentives to seek out firms in the first place. As a result, the discovery remains unused. Patent protection can change this sad state of affairs, since it allows the scientist to collect a licensing fee for her discovery. Thus, patents motivate scientists to promote their discoveries.

Though simple and elegant, this argument is also incomplete. It assumes a onesided matching process, where scientists seek out firms to promote their scientific discoveries. Presumably these discoveries constitute technological "solutions." The scientists' challenge is to find a suitable "problem," i.e., a market need that can be addressed with their scientific discoveries. It might be more efficient to have problems seeking solutions, rather than solutions seeking problems. Consider the following quote from an MIT engineer (Shane (2004b), p. 204):

With university technologies you pull the technology out and you run around saying 'Where can it stick?' It's probably much better to say I've heard about these problems and I think I can solve it. But with companies coming out of MIT, it's always the same thing, what do I do with it to shoehorn it back into industry?

Naturally, firms realize that they can do better than merely wait for scientists to find them. Indeed, there is a literature on firm's absorptive capabilities, that argues that firms invest in research capabilities, in order to find out what scientific discoveries might suit their needs (Cohen and Levinthal, 1989, 1990).

In this paper we develop a formal theory of the search and matching process between scientists and firms. The model allows us to address the role of patents in bridging the science to market gap. We do not rely on traditional incentive theories for the generation of new ideas, and therefore take the arrival rate of scientific discoveries as given. We assume that most discoveries are irrelevant for most firms, but that occasionally there is a match between a scientist and a firm. To find a match, firms and scientists invest in search. We use the term search in a broad sense. For a scientist, this includes promoting her discoveries, and making them more accessible to non-scientists. For a firm, this includes investing in absorptive capabilities (e.g. hiring managers who's role it is to interact with academia), and communicating its own technological needs. A match means that the firm has complementary assets to 
pursue a development project that is based on the scientist's discovery. If a match occurs, the scientist continues to have a role in the development process. This is because the scientist may have some tacit knowledge (or "know-how"), that improves the odds of success for the development process.

In the absence of patents, the firm can appropriate most the value from the discovery. The only source of bargaining power the scientist has comes from her tacit knowledge. In equilibrium, the firm appropriates the idea, but agrees to a consulting contract, that rewards the scientist for her continued involvement with the development process. With patents, the scientist has a much stronger bargaining position. In equilibrium the firm pays both for the license and the tacit knowledge.

In a one-sided search model, where scientists promote their ideas to firms, but not vice versa, we find that patents always increase scientists' search incentives, and thus reduce the expected time to find a match. This conclusion is easily reversed in a twosided search model, where patents promote scientists' search, but discourage firms' search. The net effect of patenting depends on the relative search efficiencies of the two parties. If the search intensity of scientists is inelastic, relative to that of firms, then patent protection actually decreases the likelihood that a scientific discovery gets developed.

This result adds to the literature on cumulative innovation. There is an important debate about the optimal allocation of intellectual property rights, when second-generation inventors require the intellectual property of a first generation of inventors. The work of Scotchmer (1991) and Green and Scotchmer (1995) shows that, if first and second generation inventors can efficiently contract with each other, then an optimal patent system should provide strong intellectual property protection to the first-generation inventors, to ensure efficient ex-ante incentives. Merges and Nelson $(1990,1994)$ question that conclusion by challenging the notion of efficient contracting between first and second generation inventors. This paper revisits the issue of cumulative innovation from a search perspective. It provides a formal model where there is a gap between first and second generation inventors. In such a model, the allocation of intellectual property rights matters, not for the usual ex-ante incentive reason, but because they affect the intensities with which first and second generation inventors are searching for each other.

So far, our discussion makes the simplifying assumption that only two parties are involved, scientists and firms. In reality, there is a third player that matters, namely 
the university. In most cases the university, not the scientist, owns the patent. The university's technology transfer office can also assume the role of an intermediary between scientists and firms.

We augment our base model by introducing the university's technology transfer office as a third player. ${ }^{3}$ The technology transfer office has a lower cost of search, because of specialization and/or because of a lower opportunity cost of time. We assume that its objective function is to maximize the university's returns. Any development contract is negotiated between three parties. The interesting question is whether or not the scientist wants to delegate the search activities to the technology transfer office. It turns out that this critically depends on whether the scientist and the technology transfer office can write complete contracts, at the beginning of the search process. If such contracts are hard to write, then we obtain the interesting result that with patent protection, the scientist gladly delegates all search activities to the technology transfer office. Without patent protection, however, the technology transfer office has no incentives to search for firms. In this case the scientist prefers to take responsibility of the search process herself. A complete contract prevents this breakdown in delegation. However, writing a complete contract might be challenging, because, without a patent, it is difficult to verify what constitutes a transfer of intellectual property.

This result about delegation is reminiscent of the historic origins of the US patent system. Lamoreaux and Sokoloff $(1999,2001)$ show that the development of patents in nineteenth century US was largely driven by the activities of patent intermediaries, who specialized in the geographic dissemination of innovations. The result on delegation also has implication for the debate whether patents encourage or discourage basic research. After carefully controlling for selection effects, Azoulay, Ding and Stuart (2005) find that patenting increases research productivity. This paper provides a novel interpretation for this result, one that does not depend on effort incentives. Patents allow scientists to delegate the promotion of their scientific discoveries to the university's technology transfer office. This frees up their time to continue pursuing their research. To the extent that the technology transfer office succeeds in finding interested firms, however, scientists may end up spending more time doing consulting.

\footnotetext{
${ }^{3}$ There are relatively few other theoretical models that explicitly examine the role of technology transfer offices. See, however, Jensen and Thursby (2001), Chukumba and Jensen (2005) and Hoppe and Ozdenoren (2005).
} 
Consistent with this, Azoulay, Ding and Stuart find that scientists who patent, are subsequently more likely to coauthor with authors in industry.

The paper is structured as follows. Section 2 lays out the base model. Section 3 derives the results for the one-side and two-sided search model. Section 4 introduces the university's technology transfer office as a third party. Section 5 discusses a variety of model extensions. It is followed by a brief conclusion.

\section{Base model}

\subsection{Base assumptions}

All parties are risk-neutral. There is an infinite horizon, and we focus on steady state equilibria. Let $\Delta$ be the length of any one period. We focus on the continuous time case, where $\Delta \rightarrow 0$. All parties use a discount rate $r \Delta$.

Suppose there is a number of scientists who all have a single scientific discovery. Each period, a discovery becomes obsolete with probability $\delta \Delta$. Each period, there are $s \Delta$ new scientists arriving, each with a single new discovery. We assume that $s$ is exogenous. This assumption means that we are ignoring any incentive effects on the scientific discovery process itself. Section 5.1 return to this issue. On its own, a scientific discovery cannot generate commercial value. ${ }^{4}$ Such value can only be created as part of a development project with a firm that has complementary assets. We assume that firms are infinitely lived. For simplicity we assume that the number of firms is fixed. We relax this in section 5.1.

Consider the issue of fit between scientific discoveries and firms. Most discoveries are irrelevant to most firms. However, there are some matches between discoveries and firms that constitute development opportunities. If there is a match between a scientific discovery and a firm, there is the additional question of what role the scientist plays. We allow for the fact that the scientist has some tacit knowledge that makes it worthwhile to involve her in the development process. ${ }^{5}$ Throughout the paper we use the subscripts $S$ and $F$ respectively for scientists and firms. The

\footnotetext{
${ }^{4}$ It is trivial to extend the model to allow the discovery to still have some value without the development by another firm. For example, the scientist might attempt to develop the discovery by herself. All that matters for the model is that search and subsequent development by another firm is more efficient.

${ }^{5}$ The work of Arora $(1995,1996)$ emphasizes the importance of tacit knowledge, and shows how patenting can further support the transfer of tacit knowledge.
} 
costs of development are given by $d_{F}$ and $d_{S}$. Let $p$ denoted the probability that development generates a usable innovation of value of $x$. With probability $1-p$, nothing valuable comes out of development. We denote the expected return from development by $\pi=p x-d_{F}-d_{S}$. We assume that if one firm invests in developing a discovery, no other firm wants to compete with it. Section 5.2. relax this assumption. If the scientist refuses to be involved in the development process, the firm may still try to develop the discovery. Using obvious notation, we denote the expected return from noncooperative development by $\pi_{0}=p_{0} x_{0}-d_{F}$. We focus on the case where the involvement of the scientist is efficient, i.e., $\pi \geq \pi_{0} \cdot{ }^{6}$

Central to the analysis is the comparison between the regimes where the scientific discovery is versus is not protected by patents. For this we assume that the existence of patents does not affect the value of $x$. We can think of the regime without patents as a regime where there is no patent protection for scientific discoveries, but there is patent protection for the innovations that firms create on the basis of scientific discoveries. Alternatively, firm innovations may be naturally protected by complementary assets or other competitive advantages. Section 5.3 discuss this further. And section 5.6 examines an extension where patent protection is imperfect.

The game consists of two main stages. At the initial search stage (which is played out in continuous time) scientists and firms incur search costs. If a discovery becomes obsolete, the game simply ends for that scientist. If there is a match between a discovery and a firm, the game progresses to the development stage. We denote the utilities at the beginning of the development stage by $u_{F}$ and $u_{S}$. The utilities at the beginning of the search stage are denoted by $U_{F}$ and $U_{S}$.

When a firm engages in development, the scientist receives a transfer $\alpha$. At the beginning of the development process, the respective utilities are given by $u_{F}=\pi-\alpha$ and $u_{S}=\alpha$. Below we derive the equilibrium value of $\alpha . \alpha$ includes the consulting fees, and possibly a payment for the intellectual property. In this simple model, it does not matter whether the transfer $\alpha$ is unconditional (such as a licensing fee), or conditional upon success (such as a royalty fee, profit-share, or equity stake). ${ }^{7}$

\footnotetext{
${ }^{6}$ The analysis for $\pi<\pi_{0}$ is straightforward. If the scientist adds no value, the exact value of $\pi$ is irrelevant, since it affect neither equilibrium outcomes nor outside options. The model with $\pi<\pi_{0}$ thus yields the same results as with $\pi=\pi_{0}$.

${ }^{7}$ To elaborate, let $a$ be the unconditional and $A$ the conditional transfer, then $\alpha=a+p A$. It is easy to see that if the scientist's development contribution is non-contractible, then incentivecompatibility requires that $p A-d_{S} \geq p_{0} A \Leftrightarrow A \geq \frac{d_{S}}{p-p_{0}}$.
} 
Central to the model is the matching process by which firms and scientists find each other. The probability that a given scientist finds a matching firm, is different from the hazard that a given firm finds a matching scientist, simply because there are different number of scientists and firms. Let $e_{S} \Delta$ be the probability that a specific scientist finds a specific firm in any one period. And let $e_{F} \Delta$ be the probability that a specific firm finds a specific scientist in any one period. We assume that all these probabilities are independent. Section 5.7 relaxes this assumption. For $\Delta$ sufficiently small, we can ignore all probabilities that multiple matches occur in the same period. ${ }^{8}$

The number of scientists and firms is denoted by $n_{S}$ and $n_{F}$. The probability that a specific scientist finds some firm with complementary assets is given by $n_{F} e_{S} \Delta$, and the probability that she is found by some firm with complementary assets is given by $n_{F} e_{F} \Delta$. Define

$$
m_{S}=n_{F} e \text { and } m_{F}=n_{S} e \text { where } e=e_{F}+e_{S},
$$

then the probability that a specific scientist finds a match in any one period is simply given by $m_{S} \Delta$. Note that $e$ represents the (instantaneous) probability that a match occurs between a specific scientist and firm. Using analogous reasoning, the probability that a specific firm finds a match in any one period is simply given by $m_{F} \Delta$.

Finding a match requires costly search efforts. The search intensities $e_{S}$ and $e_{F}$ are private non-contractible choices. The per-period cost of search is given by $\Delta c_{S}$, where we assume standard convex search costs: $c_{S}\left(e_{S}\right)$ satisfies $c_{S}^{\prime}>0, c_{S}^{\prime \prime}>0$ and $c_{S}(0)=0$; similar for $c_{F}\left(e_{F}\right)$.

We denote the utility of a scientist in period $t$ by $U_{S}(t)$. This is given by

$$
U_{S}(t)=m_{S}(t) \Delta u_{S}(t)+\left(1-m_{S}(t) \Delta-\delta \Delta\right) \frac{1}{1+r \Delta} U_{S}(t+\Delta)-c_{S}(t) \Delta
$$

In a steady state equilibrium we obtain after simple transformations

$$
U_{S}=\frac{1+r \Delta}{r+\delta+m_{S}}\left[m_{S} u_{S}-c_{S}\right]
$$

For $\Delta \rightarrow 0$ we obtain

$$
U_{S}=\frac{m_{S} u_{S}-c_{S}}{r+\delta+m_{S}}
$$

\footnotetext{
${ }^{8}$ These probabilities are all of the order $\Delta^{2}$ or higher, and naturally vanish for $\Delta \rightarrow 0$.
} 
The utility of a firm is given by

$$
U_{F}(t)=m_{F}(t) \Delta u_{F}(t)+\frac{1}{1+r \Delta} U_{F}(t+\Delta)-c_{F}(t) \Delta
$$

In steady state, with $\Delta \rightarrow 0$, we get

$$
U_{F}=\frac{m_{F} u_{F}-c_{F}}{r}
$$

Note that $U_{S}$ and $U_{F}$ have different denominators. This is because they have different time horizons. Scientists have a single idea and then exit the market. In contrast, firms participate in the market all the time, and develop all good ideas that they can find.

The number of scientists is obtained from $n_{S}(t+\Delta)=n_{S}(t)\left(1-\delta \Delta-m_{S} \Delta\right)+s \Delta$. In steady state, we obtain $n_{S}=s \frac{1-m_{S} \Delta-\delta \Delta}{\delta+m_{S}}$. For $\Delta \rightarrow 0$, we obtain

$$
n_{S}=\frac{s}{\delta+m_{S}} .
$$

The number of scientists searching for firms is larger, if there are many new discoveries (high $s$ ), little obsolescence (low $\delta$ ) and few successful matches $\left(m_{S}\right)$.

\subsection{Bargaining game}

We assume that all bilateral bargaining follows the Nash bargaining solution (Binmore, Rubinstein and Wolinsky, 1986).

If a scientist does not have a patent, the first firm with complementary assets can appropriate the discovery and develop it by itself. ${ }^{9}$ The only source of bargaining power for the scientist comes from her tacit knowledge, that can increase the expected value of development. The Nash bargaining solution immediately implies

$$
u_{F}^{N P}=\frac{\pi+\pi_{0}}{2} \text { and } u_{S}^{N P}=\frac{\pi-\pi_{0}}{2} .
$$

The superscript $N P$ refers to the no patenting regime. We use this superscript only when there is a potential confusion with the other regime where there are patents,

\footnotetext{
${ }^{9}$ In this model we assume that the scientist discloses the information only after she can ascertain that the firm is a potential match. Hellmann and Perotti (2005) examine a model where an idea generator cannot distinguish between partners that are complements or substitutes. In such a model, an idea may circulate among several agents before an appropriate match is found.
} 
which we refer to with the superscript $P$.

Consider now the case where patent protection holds. Suppose a scientist has disclosed the idea to a firm with complementary assets. The firm's outside option is simply to forgo the opportunity, which yields zero utility. The scientists outside option is to search for another firm. This effectively means starting all over again. It therefore yields the same utility as next period's ex-ante utility $\frac{1-\delta \Delta}{1+r \Delta} U_{S} \cdot{ }^{10}$ Using $\Delta \rightarrow 0$, we obtain the following Nash values

$$
u_{F}=\frac{\pi-U_{S}}{2} \text { and } u_{S}=\frac{\pi+U_{S}}{2} .
$$

Note that $\pi_{0}$ does not enter these expressions. This is because developing the discovery without the scientist is no longer an option when the scientist controls the intellectual property. Using $U_{S}=\frac{m_{S} u_{S}-c_{S}}{r+\delta+m_{S}}$ we obtain after standard transformations

$$
u_{F}^{P}=\frac{\pi(r+\delta)+c_{S}}{2(r+\delta)+m_{S}} \text { and } u_{S}^{P}=\frac{\pi\left(r+\delta+m_{S}\right)-c_{S}}{2(r+\delta)+m_{S}}
$$

Intuitively, the higher the scientist's search cost $\left(c_{S}\right)$, the weaker her bargaining power. Moreover, the higher the discount rate $(r)$ or obsolescence rate $(\delta)$, the weaker the scientist's bargaining power. ${ }^{11}$

\section{Results from the base model}

\subsection{One-sided search}

We first solve the one-sided model, where only scientists search for firms. This model assumes $e_{F}=0$. Every period the scientist maximizes $U_{S}(t)$ by optimal choice of

\footnotetext{
${ }^{10}$ Strictly speaking, this assumes that the number of potential firms $n_{F}$ is the same as before. To justify this, we can think of the number of firms being large, so that the difference between $n_{F}$ and $n_{F}-1$ is negligible. Alternatively, we can assume some loss of memory, where the scientist searches again among all firms, forgetting that she already matched with one of them in the past.

${ }^{11}$ We note that $\frac{d u_{S}^{P}}{d r} \sim \frac{d u_{S}^{P}}{d \delta} \sim\left(2 c_{S}-m_{S} \pi\right)<0$. To see that this is negative, we simply note that $U_{S}=\frac{m_{S} \frac{\pi+U_{S}}{2}-c_{S}}{r+\delta+m_{S}}>0 \Leftrightarrow m_{S} \frac{\pi}{2}-c_{S}=U_{S}\left(r+\delta+\frac{m_{S}}{2}\right)>0$.
} 
$e_{S}(t)$. The first-order condition is given by

$$
\frac{d m_{S}(t)}{d e_{S}}\left[u_{S}(t)-\frac{1-\delta \Delta}{1+r \Delta} U_{S}(t+\Delta)\right] \Delta-c_{S}^{\prime}(t) \Delta=0
$$

Using $\frac{d m_{S}(t)}{d e_{S}}=n_{F}$ we obtain

$$
n_{F}\left[u_{S}(t)-\frac{1-\delta \Delta}{1+r \Delta} U_{S}(t+\Delta)\right]-c_{S}^{\prime}(t)=0 .
$$

The first term captures the marginal benefit while the second the marginal cost. The marginal benefit naturally scales with the number of firms $n_{F}$. The most interesting term is $u_{S}(t)-\frac{1-\delta \Delta}{1+r \Delta} U_{S}(t+\Delta)$. This measures the difference in utilities between finding a partner now, versus not finding one now and continuing search.

For the steady state, using $\Delta \rightarrow 0$, we rewrite the first order condition as

$$
n_{F}\left(u_{S}-U_{S}\right)-c_{S}^{\prime}=0
$$

Proposition 1 In the one-sided search model, the effect of patent protection is to increase the scientists' search intensity $\left(e_{S}\right)$.

The proof is in the appendix. The intuition for Proposition 1 is straightforward. Patent protection increases the rents that scientists can capture from their scientific discoveries. This gives them a greater incentive to seek out firms that may be able to develop these scientific discoveries. Indeed, without patent protection, the only incentive that scientists have is to obtain a consulting contract. With a patent, they are also looking at a return for their intellectual property.

In steady state, the likelihood of finding a match is constant. This implies that the time it takes to find a match (or become obsolete) has a negative exponential distribution, with an expected waiting time of $\frac{1}{\delta+m_{S}}$. This is decreasing in $e_{S}$, which implies that patenting reduces the expected waiting time. Patenting also reduces the number of scientists actively searching, since $n_{S}$ is decreasing in $e_{S}$ (see equation (4)).

Another interesting aspect of the model concerns preferences over patent protection. Scientists always prefer to have patent protection. In most cases, firms would prefer that scientists have no patent protection, since this increases their value of development from $u_{F}^{P}=\frac{\pi-U_{S}}{2}$ to $u_{F}^{N P}=\frac{\pi+\pi_{0}}{2}$. However, there is a possibility that firms too prefer patent protection. This is because patent protection increases 
the number of matches. ${ }^{12}$

\subsection{Two-sided search}

The model with two-sided search is analogous to the one-sided model, except that scientists and firms make simultaneous search decisions. The firm maximizes $U_{F}(t)$, by choice of $e_{F}(t)$. The first order condition is given by

$$
\frac{d m_{F}(t)}{d e_{F}} \Delta u_{F}(t)-c_{F}^{\prime}(t) \Delta=0
$$

For $\Delta \rightarrow 0$, using $\frac{d m_{F}(t)}{d e_{F}}=n_{S}$, we get

$$
n_{S} u_{F}-c_{F}^{\prime}=0
$$

Note that while scientists promote a single idea, firms are always looking for many ideas. That explains why their marginal incentive is not affected by concerns of urgency. Indeed, the optimal choice of $e_{F}$ does not depend directly on $r$ or $\delta$ (although there may be an indirect effect through $u_{F}$ ).

To determine the steady state equilibrium, we also need to consider the endogenously determined number of scientist. That is, equations (4), (7) and (8) jointly determine the equilibrium values of $n_{S}, e_{S}$ and $e_{F}$. We reduce this to a system of two equations by using (4) in (8). Furthermore, from equation (2) we obtain $u_{S}-U_{S}=\frac{(r+\delta) u_{S}+c_{S}}{r+\delta+n_{F}\left(e_{S}+e_{F}\right)}$. We can therefore rewrite the two equilibrium conditions as

$$
n_{F} \frac{(r+\delta) u_{S}+c_{S}}{r+\delta+n_{F}\left(e_{S}+e_{F}\right)}-c_{S}^{\prime}=0 \text { and } \frac{s u_{F}}{\delta+n_{F}\left(e_{F}+e_{S}\right)}-c_{F}^{\prime}=0
$$

These two conditions describe the steady state reaction functions of scientists and firms. The first term describes the marginal benefit of increasing search, the second

\footnotetext{
${ }^{12}$ For example, in the absence of patent protection, for $\pi_{0} \rightarrow \pi$ we get $u_{S} \rightarrow 0$; equation (7) implies $e_{S} \rightarrow 0$, and thus $U_{F}^{N P} \rightarrow 0$. Under these circumstances, the lack of patent protection leads to a market failure, that hurts not only scientists, but also firms. More generally, we note that the utility frontier between firms and agents is analogous to that of a standard principal-agent model. A well-known result is that principals sometimes want to pay information rents (or "efficiency wages") to agents, in order to move out of any backward-bending part of the utility frontier. The same principle applies here.
} 
the marginal cost. We note that $e_{S}$ and $e_{F}$ are strategic substitutes: a higher value of $e_{F}$ reduces the marginal benefit of increasing $e_{S}$, and a higher value of $e_{S}$ reduces the marginal benefit of increasing $e_{F} \cdot{ }^{13}$

The effect of patent protection is to increase $u_{S}$ and reduce $u_{F}$. This increases the scientists' marginal benefit, whilst reducing the firms' marginal benefit. We thus obtain the following result.

Proposition 2 In the two-sided search model, the effect of patent protection is to increase the scientists' search intensity $\left(e_{S}\right)$, but to decrease the firms' search intensity $\left(e_{F}\right)$. The effect on the total search intensity $\left(e=e_{F}+e_{S}\right)$ is ambiguous. If the scientists' search behavior is sufficiently inelastic (i.e., $c_{S}^{\prime \prime}$ is sufficiently large), then patent protection reduces e.

The proof is in the appendix. Proposition 2 shows that in a two-sided model, the net effect of patenting is ambiguous. On the one hand it encourages scientists' search, on the other it discourages firms' search. Whether or not patenting increases the total probability of a match $(e)$ - and thus decreases expected the waiting time $\left(\frac{1}{m_{S}}\right)$, as well as the number of scientists actively searching $\left(n_{S}\right)$ - depends on the relative search elasticities. If scientists respond relatively little to higher expected payoffs (relative to the response of firms), then patenting fails to increase dissemination, as measured by the probability of finding a match $(e)$. The scientists' response is inelastic if $c_{S}^{\prime \prime}$ is large, i.e., if marginal search costs are sufficiently steep.

For the one-sided model we noted that if scientists' search incentives are important, then it is possible that not only scientists, but firms too, would prefer that discoveries can be patented. A symmetrical argument applies if firms' search incentives are important. In this case, it is possible that not only firms, but scientists too, would prefer that discoveries cannot be patented, because patenting may excessively reduce the firms' search incentives.

\footnotetext{
${ }^{13} \mathrm{It}$ is interesting to note that while the steady state reaction functions are substitutes, the instantaneous reaction functions are independent. To see this, we note from the instantaneous first-order condition that the choice of $e_{F}(t)$ does not depend on $e_{S}(t)$. Similarly, $e_{S}(t)$ does not depend on the contemporaneous value of $e_{F}(t)$, even though it does depend on all future values of $e_{F}(t+i \Delta)$ $(i=1,2, \ldots)$ through $U_{S}(t+\Delta)$.
} 


\subsection{Welfare analysis}

We briefly examine the welfare properties of the model. From Proposition 2, it is intuitive that the welfare impact of patenting is ambiguous in the two-sided search model. Indeed, we immediately note that patenting increases $U_{S}$, but decreases $U_{F}$, so that patenting is never a Pareto improvement. In addition to a Pareto analysis, we focus on the sum of utilities as a standard welfare criterion. However, we need to be careful to include not only the utility of all current firms $\left(n_{F} U_{F}\right)$ and all current scientists $\left(n_{S} U_{S}\right)$, but also the discounted utility of all future generations of scientists, which is given by $\sum_{t=1}^{t=\infty} s \Delta \frac{U_{S}}{(1+r \Delta)^{t}}$. For $\Delta \rightarrow 0$ we obtain after standard transformations $\frac{s}{r} U_{S}$. The social welfare function is thus given by

$$
W=n_{F} U_{F}+n_{S} U_{S}+\frac{s}{r} U_{S}
$$

Using equations (2), (3) and (4) we obtain after further transformations

$$
W=\frac{n_{S} n_{F} e \pi-n_{F} c_{F}-n_{S} c_{S}}{r}
$$

Intuitively, social welfare is given by an infinite discounted stream of instantaneous utilities, where the first term in the numerator is the instantaneous rate at which matches occur in the market $\left(n_{S} n_{F} e\right)$, times the value of a match $(\pi),{ }^{14}$ and the second and third term measure the total cost of search $\left(n_{F} c_{F}\right.$ and $\left.n_{S} c_{S}\right)$. Note that, for a given level of search intensities $\left(e_{F}\right.$ and $\left.e_{S}\right)$, the welfare function only depends on the total value of a match $\pi$, but not on the distribution of that value $\left(u_{F}\right.$ and $\left.u_{S}\right)$. This means that patenting affects welfare only through its effect on the search intensities. We derive their socially optimal levels by maximizing $W$ w.r.t. $e_{S}$ and $e_{F}$. The first order conditions are given by

$$
\begin{aligned}
& n_{S}\left[n_{F} \pi-c_{S}^{\prime}\right]+\frac{d n_{S}}{d e_{S}}\left(n_{F} e \pi-c_{S}\right)=0 \\
& n_{F}\left[n_{S} \pi-c_{F}^{\prime}\right]+\frac{d n_{S}}{d e_{F}}\left(n_{F} e \pi-c_{S}\right)=0
\end{aligned}
$$

\footnotetext{
${ }^{14}$ It is straightforward to augment the welfare function, adding $\mu$ to the value $\pi$, where $\mu$ is any additional social utility that is generated when a match occurs. For example, a development project may create some additional consumer surplus that is not captured in the profits $\pi$.
} 
The first term measures the net marginal benefit of increasing $e_{S}$ or $e_{F}$, for a given number of scientists $n_{S}$. The second term adjusts this benefit to the fact that a higher search intensity decreases the steady state number of scientists $n_{S}$. Using (4) we can rewrite these conditions as

$$
n_{F} \frac{\delta \pi+c_{S}}{\delta+n_{F} e}-c_{S}^{\prime}=0 \text { and } n_{S} \frac{\delta \pi+c_{S}}{\delta+n_{F} e}-c_{F}^{\prime}=0 .
$$

We compare these social optimality conditions with the equilibrium conditions from equation (9). The scientist has an incentive to underinvest in search, because her private benefit of finding a match is given by $u_{S}$, which is smaller than the social value of a match $\pi$. This underinvestment problem is particularly severe in the absence of patents. Interestingly, comparing (9) with (10), we also note a countervailing force, namely that a higher discount rate $(r)$ creates urgency for the scientist, which increases her search intensity $e_{S}$, without affecting the socially optimal value in equation (10). For low values of $r$, there is underinvestment in the scientist's search, although for high values of $r$, there may be overinvestment.

For the firm's search, we also detect some ambiguity about under- versus overinvestment. Straightforward calculations reveal that firms underinvest whenever $u_{F}<$

$\frac{\delta \pi+c_{S}}{\delta+n_{F} e}$. This condition is more likely to be satisfied when there are patents, although it may still be satisfied, even when there are no patents (such as when $\delta$ is large).

In summary, the welfare conditions show that, depending on parameters, underinvestment and overinvestment may occurs, for scientists or for firms. The net effect of patenting is inherently ambiguous, since it can bring the equilibrium levels of search either closer or further away from their socially optimal levels.

\section{The role of the technology transfer office}

So far the analysis makes the simplifying assumption that scientists own the patents, and that they search for firms by themselves. We now consider a richer and more realistic set-up, where there is a third player, namely the university's technology transfer office (TTO henceforth). In most cases, it is the university, not the scientist, that owns the patent. Broadly speaking, this is true whenever the scientific discoveries were obtained making use of university resources. The role of the TTO is to adminis- 
ter the university's patent portfolio, as well as to provide some intermediation services for the transfer of technology. Concretely, the TTO performs a variety of tasks. It often takes care of administrative steps, such as the filing of patents. It negotiates with the scientist. Even though the university owns the patent, the TTO may still share the rewards with the scientist, especially if her participation is required at the development stage. Moreover, the TTO may take over the process of identifying firms interested in developing the technology. That is, in many cases, it is not so much the scientist as the TTO that engages in the search activities we have described so far.

The objective of this paper is not to model all the intricacies of how a TTO operates, but, more specifically, to examine how the presence of a TTO affects the matching process between scientific discoveries and firms. To achieve this objective, we have to make a number of modelling choices. It is likely that a TTO has a comparative advantage at identifying potential partner firms. This is because it can hire managers who specialize in that task, and who do not have the competing time pressures of pursuing scientific research itself. We therefore assume that the TTO is more efficient at search. In section 5.5, we show how to relax this assumption. Using obvious notation, the TTO has search $\operatorname{costs} c_{T}\left(e_{T}\right)$, again with $c_{T}(0)=0, c_{T}^{\prime}>0$ and $c_{T}^{\prime \prime}>0$. We also assume that $e_{S}$ and $e_{T}$ are duplicative, so that either the scientist or the TTO would want to search, but not both.

One obvious advantage of having a TTO is that it probably makes it easier for firms to find scientific discoveries. That is, the presence of a centralized office that provides information on research activities facilitates firms' search. This is likely to reduce $c_{F}$.

In the neoclassical tradition of presuming selfish economic behavior, we assume that the TTO maximizes the returns of its owner, which is the university. Thus, the TTO equates the university's marginal benefits of finding a match with its marginal cost of searching. It does not take into account any benefits to the scientist, let alone to potential partner firms. ${ }^{15}$

At the time of negotiating the development contract, there are now three parties

\footnotetext{
${ }^{15}$ This assumption is somewhat stylized, in the sense that technology transfer offices, at the minimum, pay lip service to the notion that they balance the interests of the university, the scientists, and possible even industry. Using the assumption of selfish behavior has the benefit of clarity. Relaxing it also entails some technical difficulties, since it requires defining a utility function over other player's utility functions, and then using this to solve the Shapley bargaining game.

Another interesting point to note is that even if the TTO behaves selfishly, the optimal contract induces the TTO to internalize the scientist's concerns, as shown below.
} 
at the bargaining table: the firm who has the complementary asset, the scientist who might have some valuable tacit knowledge, and the TTO who owns the patent (if there is one). We assume that the three parties divide the returns according to the Shapley solution (Hart and Mas-Collel, 1986).

Another modelling choice concerns the degree of contractual completeness. The recent contracting literature has debated this with a lot of verve. In section 4.1 we examine the incomplete, and in section 4.2. the complete contracting model. In section 4.3., we explore more deeply the differences in the underlying assumptions, and discuss their reasonableness in the specific context of scientists contracting with their TTO.

The time line of the model with incomplete contracts is as follows. The scientist discloses a scientific discovery to the TTO (we revisit this in section 5.4). A patent is filed at this point (provided there is patent protection). The TTO then searches for a firm with complementary assets. Once a match is found, the firm, the TTO, and the scientist bargain over access to the intellectual property, as well as a consulting agreement. The timeline of the complete contract model is the same, except that the scientist and TTO can write a contract at the beginning of the search stage. Since the complete contracts model builds on the incomplete contracts model, we begin with the latter.

\subsection{Incomplete contracts}

To solve the model, we first solve the bargaining game at the beginning of the development stage. This is a three-person bargaining game between the firm, the scientist, and the TTO. To apply the Shapley value, we need to examine all possible subcoalitions.

Consider first the case with patent protection. The value of the grand coalition, denoted by $v_{F S T}$, is the expected return from development, i.e., $v_{F S T}=\pi$. The value of the sub-coalition involving the firm and the scientist is $v_{F S}=0$, since they cannot develop the discovery without access to the intellectual property. The value of the subcoalition involving the firm and the TTO is given by $v_{F T}=\pi_{0}$, which is the expected return when development occurs without the scientist's involvement. The value of the sub-coalition involving the scientist and the TTO is given by $v_{S T}=U_{S}^{P}+U_{T}^{P}$,

where from $(2)$, the respective ex-ante utilities are given by $U_{S}^{P}=\frac{m_{T}^{P} u_{S}^{P}}{r+\delta+m_{T}^{P}}$ and 
$U_{T}^{P}=\frac{m_{T}^{P} u_{T}^{P}-c_{T}^{P}}{r+\delta+m_{T}^{P}}$. The idea is that if the firm is excluded, the scientist and the TTO simply have to start afresh and find a new partner. The value of the firm alone is $v_{F}=0$ and the value of the scientist alone is $v_{S}=0$, since neither party has the intellectual property. Interestingly, the TTO alone can generate some value, since it can try to find a new firm, and then license out the technology without the scientist's cooperation. We use the subscript $T \backslash S$ to denote all outcomes that are associated with the TTO acting alone, and write $v_{T}=U_{T \backslash S}^{P} \cdot{ }^{16}$

In general, the Shapley value is given by

$$
\begin{aligned}
& u_{F}=\frac{1}{3}\left(v_{S T F}-v_{S T}\right)+\frac{1}{6}\left(v_{S F}-v_{S}\right)+\frac{1}{6}\left(v_{T F}-v_{T}\right)+\frac{1}{3} v_{F} \\
& u_{S}=\frac{1}{3}\left(v_{S T F}-v_{T F}\right)+\frac{1}{6}\left(v_{S F}-v_{F}\right)+\frac{1}{6}\left(v_{S T}-v_{T}\right)+\frac{1}{3} v_{S} \\
& u_{T}=\frac{1}{3}\left(v_{S T F}-v_{S F}\right)+\frac{1}{6}\left(v_{T F}-v_{F}\right)+\frac{1}{6}\left(v_{S T}-v_{S}\right)+\frac{1}{3} v_{T}
\end{aligned}
$$

Applying this to the model with patents, we obtain

$$
\begin{aligned}
& u_{F}^{P}=\frac{1}{3} \pi-\frac{1}{3}\left(U_{S}^{P}+U_{T}^{P}\right)+\frac{1}{6} \pi_{0}-\frac{1}{6} U_{T \backslash S}^{P} \\
& u_{S}^{P}=\frac{1}{3} \pi-\frac{1}{3} \pi_{0}+\frac{1}{6}\left(U_{S}^{P}+U_{T}^{P}\right)-\frac{1}{6} U_{T \backslash S}^{P} \\
& u_{T}^{P}=\frac{1}{3} \pi+\frac{1}{6} \pi_{0}+\frac{1}{6}\left(U_{S}^{P}+U_{T}^{P}\right)+\frac{1}{3} U_{T \backslash S}^{P}
\end{aligned}
$$

This describes the utilities for the development stage. ${ }^{17}$

To complete the model, we note that the equilibrium is again described by equations (4), (7) and (8) except that we use $e_{T}$ and $c_{T}$, instead of $e_{S}$ and $c_{S}$.

We can contrast this equilibrium with the equilibrium that obtains in the regime without patents. Patenting affects the value of sub-coalitions, and has therefore an important effect on relative bargaining power. The value of the grand coalition

${ }^{16}$ To calculate the value of $U_{T \backslash S}^{P}$, from (2), we have $U_{T \backslash S}^{P}=\frac{m_{T \backslash S}^{P} u_{T \backslash S}^{P}-c_{T \backslash S}^{P}}{r+\delta+m_{T \backslash S}^{P}}$, and, from (6), we have $u_{T \backslash S}^{P}=\frac{\pi_{0}\left(r+\delta+m_{T \backslash S}^{P}\right)-c_{T \backslash S}^{P}}{2(r+\delta)+m_{T \backslash S}^{P}}$. Moreover, $e_{T \backslash S}$ replaces $e_{S}$ in $(7)$.

${ }^{17}$ Note that $\left(U_{S}^{P}+U_{T}^{P}\right)$ depends on $u_{S}^{P}$ and $u_{T}^{P}$. It is tedious but straightforward to simultaneously solve the second and third equation, to obtain $U_{S}^{P}+U_{T}^{P}=$ $\left(4 \pi-\pi_{0}+U_{T \backslash S}^{P}\right) m_{T}^{P}-2 \frac{3 r+3 \delta+4 m_{T}^{P}}{3 r+3 \delta+3 m_{T}^{P}} c_{T}^{P}$

$$
6 r+6 \delta+4 m_{T}^{P}
$$

solutions for $u_{F}^{P}, u_{S}^{P}$ and $u_{T}^{P}$.

Replacing this in (11) provides an expression of the 
remains the same, i.e., $v_{F S T}=\pi$. The value of the sub-coalition involving the firm and the scientist is also given by $v_{F S}=\pi$, since without patent rights, the TTO cannot prevent development to occur. The value of the sub-coalition involving the firm and the TTO is again given by $v_{F T}=\pi_{0}$. The value of the sub-coalition involving the scientist and the TTO is now given by $v_{S T}=0$, since the firm can always develop the discovery on its own. Indeed, that is why we also have $v_{F}=\pi_{0}$ and $v_{S}=v_{T}=0$. Using these coalition values, we obtain the following Shapley values for the model without patents:

$$
u_{F}^{N P}=\frac{\pi+\pi_{0}}{2}, u_{S}^{N P}=\frac{\pi-\pi_{0}}{2} \text { and } u_{T}^{N P}=0 .
$$

We immediately note that the TTO obtains nothing, and that the firm and the scientist obtain the same bargaining shares as in (5). The reason for this is simple, but profound: without patents, the TTO creates no additional value, after a match has been made. This means that it wields no bargaining power, and hence obtains no returns. Naturally, this affects its incentives at the search stage. From (7) we immediately note that the optimal choice is simply $e_{T}=0$ : without the prospects of any rewards, the TTO is simply unwilling to invest in search.

Comparing the equilibrium outcomes with and without patents, we obtain the following important result:

Proposition 3 With incomplete contracts, the effect of patenting is to enable delegation of search activities to the TTO. Without patents, delegation is impossible.

\subsection{Complete contracts}

The previous section assumed a contractual incompleteness, where at the beginning of the search stage, the scientist and the TTO do not write any contracts that govern the search process. We now examine the case of complete contracts, where the scientist and the TTO can write a contract that specifies rewards for successfully identifying a development partner. Such a contract only involves the scientist and the TTO. There always remains a more fundamental contractual incompleteness, namely that at the search stage these two parties cannot write a contract with potential partner firms, simply because they don't know who the relevant partner is.

Suppose now that it is possible to write a contract that specifies a transfer $\tau_{1}$ from the scientist to the TTO, in case of a successful match. In addition, let $\tau_{0}$ denote any 
ex-ante transfer from the scientist to the TTO. For simplicity we assume no wealth constraints, nor any other contractual limitations, so that $\tau_{1}$ and $\tau_{0}$ can take on any positive or negative value. We denote the utilities in the complete contracts model with a tilde, so that $\widetilde{u}_{S}=u_{S}-\tau_{1}, \widetilde{u}_{T}=u_{T}+\tau_{1}$. Moreover, $\widetilde{U}_{S}=U_{S}\left(\tau_{1}\right)-\tau_{0}$ and $\widetilde{U}_{T}=U_{T}\left(\tau_{1}\right)+\tau_{0}$, where $U_{S}\left(\tau_{1}\right)=\frac{m_{T} \widetilde{u}_{S}}{r+\delta+m_{T}}$ and $U_{T}\left(\tau_{1}\right)=\frac{m_{T} \widetilde{u}_{T}-c_{T}}{r+\delta+m_{T}}$.

Proposition 4 With complete contracts, delegating search to the TTO is always optimal, with or without patenting. The optimal contract always allocates all the benefits from finding a match to the TTO. We have $\tau_{1}^{*}=u_{S}>0$, so that $\widetilde{u}_{S}=0$ and $\widetilde{u}_{T}=u_{T}+u_{S}$. Moreover, the optimal contract compensates the scientist through an ex-ante transfer, i.e., $\tau_{0}^{*}<0$.

The proof is in the appendix. Proposition 4 establishes that, irrespective of the patenting regime, a complete contract allows the scientist to always delegate search activities to the TTO. The optimal contract specifies that the scientist transfer all her utility from a match $\left(u_{S}\right)$ to the TTO. This utility includes not only any patenting rights (there are none in the no patenting regime anyway), but also any surplus that the scientist might obtain from her tacit knowledge. This means that the only compensation that the scientist receives from a match is a small payment to cover her development costs $d_{S}$. Transferring all the utility from a match to the TTO is efficient, since the TTO becomes the residual claimant of the joint benefits of finding a match. That means that the TTO has privately optimal incentives for search, since it internalizes the scientist's benefits. Naturally, in order to give up the utility from a match, the scientist receives an up-front compensation $\left(\tau_{0}<0\right)$.

\subsection{Discussion}

In this section we discuss how reasonable complete contracts are in the specific context of our model. The most critical assumptions is that it is possible to make a transfer $\tau_{1}$, that is contingent on finding a true match. Consider first the case where there are patents. The verifiable event that triggers the transfer $\tau_{1}$ is the licensing (or sale) of the intellectual property rights to a firm that wants to further develop the scientific discovery. It seems reasonable to suppose that the scientist and the TTO can specify such a contingency in their initial agreement, given that licensing of a specific technology is a tightly defined event. We contrast this with the case where 
there are no patents. In this case, there won't be any licensing contract. The only contract that is likely to occur is a consulting agreement between the scientist and the firm. Turning a consulting contract into the verifiable event that triggers the transfer payment $\tau_{1}$, however, is much more problematic. Unlike with licensing, it is much harder to ascertain whether a consulting agreement pertains to a specific discovery. Once the TTO has found a match, the scientist has an incentive to engage in a consulting agreement with the firm, but claim that this consulting agreement is unrelated to the original discovery. This avoids paying the transfer payment $\tau_{1}$. In fact, it may even be possible for the scientist not to disclose to the university that any consulting agreement has been signed, or to structure the consulting agreement through a third party, such that it can no longer be traced to the specific firm. ${ }^{18}$

The interesting point is that the assumption of whether the scientist and the TTO can reasonably write an ex-ante contract depends itself on the patenting regime. A benefit of having patents is that it facilitates the writing of contracts, because the licensing of a patent provides a verifiable event itself. This suggests the conclusion that if patents exist, delegation to the TTO is always possible. The patent facilitates the writing of a complete contact, which allows the TTO to internalize the joint benefits of search. In this case, the model with the TTO essentially mirrors the model of section 3, with search being performed by the TTO. However, if no patents exists, then the scientist and the TTO might find it is difficult to write complete contracts. This may lead to a break-down of delegation. In this case, the model with the TTO also mirrors the model of section 3 , but with search being performed by the scientist herself.

The discussion so far focusses on the difficulties with the contingent transfer $\tau_{1}$. There may be another set of problems with the unconditional transfer payment $\tau_{0}$. The optimal contract requires that the TTO pays the scientist for her discovery. This can lead to an adverse selection problem, where every scientist in the university suddenly "claims" to have a discovery, that deserves to be compensated by the TTO. To prevent adverse selection, the TTO compensates only those discoveries that prove to have development potential. That means no ex-ante transfers to the scientist, i.e.,

\footnotetext{
${ }^{18}$ Purists may object that if intellectual property is verifiable to a patent office (or a patent court), then it should also be verifiable in private contracts (or a civil court). However, patenting has a much more standardized process, suggesting lower costs of contracting. And patenting has welldefined rules and regulations, as well as a substantial amount of precedence, which creates better enforceability.
} 
$\tau_{0} \geq 0 .{ }^{19}$

If adverse selection prevents unconditional transfer payments to scientists, we have a constrained contracting model. We briefly outline the main insights from such a model. It is easy to see that the optimal $\tau_{0}$ satisfies $\tau_{0}=0$ (or equivalently $\tau_{0} \rightarrow 0$ ). This is because the scientist sees no need or desire to compensate the TTO. If it is impossible to contract on $\tau_{1}$ (as discussed above), then there is no room for any ex-ante contract, and the model reverts to the incomplete contract model. But even if contracting on $\tau_{1}$ is possible, the model easily reverts to the incomplete contract model. To see this, note that the scientist can offer some incentive compensation $\left(\tau_{1}>0\right)$ to the TTO, but she can never get the TTO to pay for it. For many parameters, the scientist therefore simply refuses to make any contingent payments to the TTO $\left(\tau_{1}=0\right)$. In the appendix we derive the formal condition for when the scientist sets $\tau_{1}=0$ versus $\tau_{1}>0$. We also show that even if $\tau_{1}>0$, the optimal incentives always fall short of the first-best level, i.e., $\tau_{1}<\tau_{1}^{*}$.

\section{Model extensions}

\subsection{Endogenizing the number of firms and discoveries}

So far we assumed that the number of firms $\left(n_{F}\right)$, and the number of new discoveries $(s)$ is exogenous (although the number of scientist that remain in the market $\left(n_{S}\right)$ is endogenous). We now discuss how the model can be extended to allow both of these to be determined endogenously.

To endogenize the number of firms, suppose an investment is required to develop some complementary assets, that allow a firm to become a potential partner, i.e., to become a member of the relevant set of firms $n_{F}$. Specifically, suppose that firms have to incur some fixed cost $k \in[0, \infty)$, and that the distribution of fixed costs is characterized by $K(k)$. The entry condition is given by $U_{F} \geq k$, and the number of firms is endogenously given by $n_{F}=K\left(U_{F}\right)$.

The supply of patentable discoveries may also be endogenous. The literature

\footnotetext{
${ }^{19}$ It is straightforward to model this formally. Assume that there are two types of discoveries that the TTO cannot distinguish ex-ante. One is truthful, as described in the main model. The other one is fake, never generates any value, and never attracts any partner firm. Suppose that the number of potential fake discoveries is large. To induce self-selection, the TTO can offer any $\tau_{0}>0$ (including $\tau_{0} \rightarrow 0$ ), but it cannot offer any $\tau_{0}<0$.
} 
has identified two main reasons why the return to patents may affect incentives for research. One hypothesis is that patents induce greater work effort. This corresponds to the traditional ex-ante argument for patenting. As discussed in the introduction, it is not clear that provision of effort is a major concern for scientists. A second, and potentially more important incentive effect relates to a multi-tasking choice between basic research, which is assumed to be unpatentable, and applied research, which may potentially lead to a patent. For simplicity suppose that each scientist chooses one of two career paths. The relative aptitudes and preferences for doing basic versus applied research can be described by the following simply utility function: $\Upsilon_{S}=$ $\operatorname{Max}\left[a\left(U_{S}\right), b\right]$, where $a\left(U_{S}\right)$ is the return to applied research, and $b$ the expected utility of doing basic research. Suppose that $b$ has a distribution $B(b)$ over $[0, \infty)$. A scientist pursues an applied research agenda whenever $a\left(U_{S}\right) \geq b$. Let $s(B)$ denote the number of new applied discoveries that are generated if $B$ scientists are dedicated to applied research. Since $s(B), B(a)$ and $a\left(U_{S}\right)$ are all increasing functions, the supply of new discoveries $s$ is an increasing function of $U_{S}$. We write $s\left(U_{S}\right)$, which is a short-hand for $s\left(B\left(a\left(U_{S}\right)\right)\right)$.

Consider now the model where both the number of firms and discoveries is endogenous. We augment the equilibrium conditions with the additional equations $n_{F}=K\left(U_{F}\right)$ and $s=s\left(U_{S}\right)$. We have already seen that the effect of patenting is to increase $u_{S}$, and to decrease $u_{F}$. Moreover, patenting increases $U_{S}$ and decreases $U_{T} \cdot{ }^{20}$ If the number of firms and scientists is endogenous, patenting has some additional effects. A higher value of $U_{S}$ increases the supply of applied researchers, increasing the arrival rate of new discoveries. Similarly, a lower value of $U_{F}$ decreases the supply of firms that are willing to invest in complementary assets. In addition to affecting the (ex-post) search intensities, patenting thus affects the (ex-ante) investment decisions. The effects are in line with the standard results from the ex-ante literature, in the sense that patenting increases the supply of discoveries. In addition, our model also shows that patenting can result in a decrease of firms with complementary assets. Again, we note that the net effect of patenting is inherently ambiguous.

\footnotetext{
${ }^{20}$ In section 3 we also discussed some minor exceptions to this, where the utility frontier is backward bending. For brevity's sake, we omit the discussion of this case.
} 


\subsection{Competitive development}

The main model assumes that development is a natural monopoly. The first firm to be matched with the right scientist develops the discovery. No other firm finds it worthwhile to attempt a competitive development effort. We now briefly discuss how to relax this assumption and allow for competition in development. Since the effects of competition have been noted before in the large literature on patent races, we limit the discussion to a highly stylized model, that quickly generates the main insights.

Suppose that instead of one, there may be up to two firms that could develop a scientific discovery. We assume that the two firms are symmetric, and that their success probabilities $p$ are independent of each other. With probability $p^{2}$, both development projects are successful, and the two firms compete in a Bertrand fashion, generating zero profits. With probability $p(1-p)$ the first firm is alone to develop successfully. The expected profits under competition are thus given by $\pi^{c}=p(1-$ p) $x-d_{F}-d_{S} \cdot{ }^{21}$ With a patent, the scientist chooses to either license the intellectual property to two competing firms, or alternatively to give one firm an exclusive license. For the monopoly case, we denote the expected profits by $\pi^{m}=p x-d_{F}-d_{S}$.

To stay close to the structure of the main model, we assume that before a match is found, the search process is the same as before. Moreover, once a firm and scientist are matched, and once they have agreed to cooperate on a development project, we assume that it becomes easy to identify all other firms that could initiate a competing development project. We assume that there are many potential competitors for the second development project, so that the scientist can extract all profits from the second licensee. ${ }^{22}$ The condition for when the scientist wants to grant competitive licenses is simply given by $2 \pi^{c}>\pi^{m} \Leftrightarrow d_{S}+d_{F}<\left(p-2 p^{2}\right) x$. This requires that development costs are not too high, so that their duplication is not too wasteful. The model with competitive licenses is essentially the same as the model of section 3, except that the value of a match is now given by $\pi=\operatorname{Max}\left[\pi^{m}, 2 \pi^{c}\right]$.

The model with competition highlight two additional effects of patenting. Competitive development is socially efficient whenever $\left(2 p-p^{2}\right) x-2\left(d_{F}+d_{S}\right)>p x-$

\footnotetext{
${ }^{21}$ If the scientist withholds her tacit knowledge to one of the two firms, then the two competitors would have asymmetric profits $\pi^{c+}=p\left(1-p_{0}\right) x-d_{F}-d_{S}$ and $\pi^{c-}=p_{0}(1-p) x-d_{F}$. For brevity's sake, we omit the discussion of this case.

${ }^{22}$ We continue to assume that the first firm has some bargaining power. For example, the first firm might know the identities of potential other licensees, but not disclose this information until it has secured its own licensing agreement.
} 
$\left(d_{F}+d_{S}\right) \Leftrightarrow\left(d_{F}+d_{S}\right)<\left(p-p^{2}\right) x$. Without patents, there always is a second firm that sets up competitive development. The first effect is that patenting can sometimes prevent inefficient cost duplication. This happens whenever $\left(d_{F}+d_{S}\right)>$ $\left(p-p^{2}\right) x$. In this case, patenting has the advantage of preventing socially wasteful cost duplication. The second effect is that patenting can sometimes create inefficient monopolization. Specifically, for $\left(p-2 p^{2}\right) x<\left(d_{F}+d_{S}\right)<\left(p-p^{2}\right) x$, the scientist prefers exclusive licensing, even though competitive licensing is socially efficient.

\subsection{The protection of final product rents}

So far, we used the assumption that if a firm is the only one to successfully develop a discovery, then it enjoys a profit $x$, where $x$ does not depend on the existence or absence of a patent. We now briefly discuss what happens when we relax this assumption. The main issue that arises is rent dissipation. If it is possible for competing firms to imitate the final product, then $x$ can depend on patents. Let $x^{P}$ and $x^{N P}$ be the profits with and without patents. If imitation is perfect, then, in the absence of patenting, Bertrand competition generates $x^{N P}=0$. More generally, patents may help to protect the returns from development, so that $x^{P}>x^{N P}$. A lower return to development without patents, might affect the firm's willingness to incur development

costs in the first place. In particular, if $x^{N P}<\frac{d_{F}+d_{S}}{p}$, then no firm is ever willing to develop a scientific discovery without patent protection. In this case, patenting is always efficient, since without patenting, the development process collapses.

This line of reasoning was central for the passage of the Bayh-Dole act. While the argument is economically plausible, our formal model helps to clarify the underlying assumptions that are required for this result. It must be true that patents on scientific discoveries are effective in protecting the value of the final product. And it must be true that, in the absence of these patents, firms are unable to protect the value of the final product. This set of assumptions may be valid under specific circumstances - e.g., the argument has some appeal for drug development - but it is not so clear how broadly the argument applies in many other settings. Indeed, for the 'Bayh-Dole' rationale to hold, it must be that only the scientific discovery is patentable, but not the final product. It is unclear why, in general, patenting of scientific discoveries should be easier than patenting of final products. If the final product is patentable, then the simple 'Bayh-Dole' reasoning does not apply, and we have to examine the more 
subtle trade-offs that we derived in our main model. And even if it is impossible to patent the final product, the simple 'Bayh-Dole' rationale may still not apply, namely when firms can create other competitive advantages, such as assets, tacit knowledge, or time to market, that allow them to protect the value of the final product.

The discussion of this and the previous section also helps to clarify some confusion in the seminal work of Kitch (1977). Kitch seems to simultaneously argue that patents help to overcome an overinvestment problem, where too many firms would invest in a discovery otherwise, and an underinvestment problem, where firms would be unwilling to invest otherwise. The underinvestment argument pertains to the model with rent dissipation, where $x^{N P}<\frac{d_{F}+d_{S}}{p}$. By contrast, the overinvestment argument essentially assumes no rent dissipation $\left(x^{N P}=x^{P}\right)$, but instead assumes inefficient cost duplication $\left(\left(d_{F}+d_{S}\right)>\left(p-p^{2}\right) x\right)$. Our formal analysis hopes not only to clarify Kitch's confusion, but also to present a more balanced and comprehensive framework, that allows us to examine the ex-post advantages and disadvantages of patenting.

\subsection{Voluntary disclosure}

So far, in the model with the TTO, we assumed that the scientist is willing to disclose her discovery to the university. Without patent protection, disclosure is irrelevant, but with patent protection, disclosure is the first step towards a patent application. Instead of disclosing her discovery, the scientist can search by herself for a partner firm. The major drawback is that without disclosure, the scientist never wants to file a patent, since the university would simply lay a claim on it. The best the scientist can expect without disclosure is thus to get a consulting contract.

To analyze the disclosure decision, consider first the case of incomplete contracts. With disclosure the scientist's utility is given by $U_{S}^{P}=\frac{m_{T} u_{S}^{P}}{r+\delta+m_{T}}$ where $u_{S}^{P}=$ $\frac{1}{3} \pi-\frac{1}{3} \pi_{0}+\frac{1}{6}\left(U_{S}^{P}+U_{T}^{P}\right)-\frac{1}{6} U_{T \backslash S}^{P}$. Without disclosure, using obvious notation, the scientist obtains $U_{S \backslash T}^{N P}=\frac{m_{S \backslash T} u_{S \backslash T}^{N P}-c_{S \backslash T}}{r+\delta+m_{S \backslash T}} \quad$ where $u_{S \backslash T}^{N P}=\frac{\pi-\pi_{0}}{2}$. The scientist benefits from disclosure whenever $\frac{m_{T} u_{S}^{P}}{r+\delta+m_{T}}>\frac{m_{S \backslash T} u_{S \backslash T}^{N P}-c_{S \backslash T}}{r+\delta+m_{S \backslash T}}$. This condition is easily satisfied, such as when the scientist has large search costs $c_{S \backslash T}$.

The most interesting issue is whether the condition can ever be violated, so that 
the scientist refused to disclose her discovery. To show that this is indeed possible, let us focus on the case where tacit knowledge is important. Specifically, we consider the case where $\pi_{0} \rightarrow 0$. This implies $U_{T \backslash S}^{P} \rightarrow 0$, so that $u_{S}^{P}-u_{S \backslash T}^{N P}=\frac{1}{6}\left(U_{S}^{P}+U_{T}^{P}-\pi\right)<0$ (since $\pi>u_{S}^{P}+u_{T}^{P}>U_{S}^{P}+U_{T}^{P}$ ). This says that for the scientist, disclosure has a disadvantage in terms of a lower return from finding a match. Naturally, one advantage of disclosure is that it saves the scientist the cost of search $\left(c_{S \backslash T}\right)$. To fully assess the disclosure decision, we also need to know whether delegation to the TTO results in a higher probability of finding a match. The values $m_{T}$ and $m_{S \backslash T}$ depend both on marginal benefits and costs. On the benefits side, we note that for $\pi_{0} \rightarrow 0$, we have $u_{T}^{P} \rightarrow u_{S}^{P}<u_{S \backslash T}^{N P}$. This says that the TTO has a lower benefit than the scientist. If the TTO has a sufficiently large cost advantage over the scientist, we may still obtain $m_{T}>m_{S \backslash T}$. But for a sufficiently small cost advantages, we obtain $m_{T}<m_{S \backslash T}$. Suppose now that the scientist's search costs are sufficiently small, and sufficiently close to the TTO's costs. In this case the advantages of disclosure are small, but the disadvantage of disclosure remain large. We have thus constructed an example where the scientist prefers not to disclose her discovery, in order to avoid having to share returns with the TTO. Non-disclosure obviously negates any benefits of patenting, since the equilibrium reverts to the no patenting outcome.

In the model with complete contracts, disclosure becomes relatively more attractive to the scientist. This simply follows from the fact that at the initial bargaining stage with the TTO, the scientist has, as her outside option, the utility of the incomplete contracts model. In the negotiation she receives a utility higher than this outside option. Hence disclosure becomes relatively more attractive.

So far we assumed that the scientist remains with the university. An additional complication arises if the scientist can leave the university and pretend that the discovery was made after leaving. The feasibility of this obviously depends on the nature of the discovery, but the option of leaving can become an attractive alternative to disclosure. This problem applies especially for graduate students. A curious and unintended consequence of university patenting might be the departure of talented researchers, who want to avoid disclosing their scientific discoveries to the university's TTO. 


\subsection{Spin-offs}

The model of section 4 assumes that the TTO is more efficient at search than the scientist. This may be reasonable in many situations, but not all. We now briefly examine the case where the scientist is more efficient. In this case, delegation to the TTO is inefficient. At the beginning of the search stage, the scientist and the TTO can make a joint decision about the efficient allocation of intellectual property rights. It is immediate that the optimal outcome is for the TTO to transfer the intellectual property rights back to the scientist. With control over her intellectual property rights, the scientist has privately efficient incentives to search for a potential partner firm.

Licensing back to the scientist is efficient whenever, using obvious notation, $U_{S}^{\text {spin }}>$ $U_{S}+U_{T}$. In a spin-off, the scientist always internalizes all benefits from search. In the case of complete contracting, the TTO also internalizes all benefits from search. It immediately follows that a spin-off is efficient whenever $c_{S}^{\prime}<c_{T}^{\prime}$. In the case of incomplete contracts, there is an additional inefficiency with a TTO-led search, namely that the TTO fails to internalize some of the benefits from search. This means that even if the scientist has slightly higher search costs, a spin-off may still be more efficient than a TTO-led search.

Our model can thus account for another common empirical phenomenon, namely that a TTO sometimes licenses the intellectual property back to the scientist, who then forms a spin-off company. Shane (2004b) provides a detailed analysis of such university spin-offs. An important insight from our analysis is that we need not think of a spin-off as the creation of a company, that wants to develop the scientific discovery by itself. Instead, we can think of a spin-off as a mechanism for organizing the search for a corporate partner, who will then undertakes the development, as part of a strategic alliance with the spin-off company.

\subsection{Imperfect patent protection}

So far we assumed that either there is no patent protection, or patent protection is perfect. We now consider the case of imperfect patent protection. For this, we use a simple model of imperfect enforceability. We allow for efficient pre-trial bargaining, and we assume common priors. To model the uncertainty in the court system, let $q$ be the probability that a court upholds the patent. It is convenient to express the 
expected legal costs as a fraction of the value at stake $x$, i.e., suppose legal costs are given by $\psi_{F} x$ and $\psi_{S} x$, where $\psi_{F}, \psi_{S} \in(0, \infty)$. If the patent is upheld, we assume that the offender has to pay the patentee a licensing fee of $\lambda x$, where $\lambda \in(0, \infty)$. If the court revokes the patent, the alleged offender can proceed freely. Prior to going to court, the two parties can settle. The expected utilities of going to court are given by $q \lambda x-\psi_{S} x$ and $x-q \lambda x-\psi_{F} x$. Note that for $q<\frac{\psi_{S}}{\lambda}$, the threat of going to court is never credible, since the cost outweigh the expected benefits. In this case the firm can simply ignore the patent, which is de facto not enforceable. For $q>\frac{1-\psi_{F}}{\lambda}$, the firm prefers not to infringe, rather than be dragged into court. In this case, the firm always agrees to obtain a license up-front. The patent is de facto perfectly enforceable.

Consider now the intermediate case where $\frac{\psi_{S}}{\lambda}<q<\frac{1-\psi_{F}}{\lambda}$. In this case, the two parties would prefer to settle out of court. The gains from a pretrial settlement are the legal cost savings $\left(\psi_{F}+\psi_{S}\right) x$. The Nash bargaining solution yields $q \lambda x-\psi_{S} x+\frac{1}{2}\left(\psi_{F}+\right.$ $\left.\psi_{S}\right) x=\left(q \lambda+\frac{\psi_{F}-\psi_{S}}{2}\right) x$ and $x-q \lambda x-\psi_{F} x+\frac{1}{2}\left(\psi_{F}+\psi_{S}\right) x=\left(1-q \lambda-\frac{\psi_{F}-\psi_{S}}{2}\right) x$.

At the beginning of development stage, the two parties can sign a licensing agreement. Strictly speaking, the firm is indifferent between striking a licensing agreement, or waiting for a pre-trial bargaining. We focus on the more intuitive scenario, where the firm agrees to take a license up-front, but pays a reduced fee that reflects imperfect enforceability. The transfer $\alpha$ satisfies $u_{S}=\alpha=p x\left(q \lambda+\frac{\psi_{F}-\psi_{S}}{2}\right)-d_{F}$, which is an increasing function of $q$. By varying $q$, the model with imperfect enforceability spans the spectrum from no patent protection to perfect patent protection. Put differently, for every $\alpha \in\left[0, u_{S}^{P}\right]$, we can find a corresponding $q$ that generates that value of $\alpha$. The model with imperfect patent protection therefore convexifies the discrete distinction between the no patent and the perfect patent regime.

The analysis of imperfect patents has another interesting implication. From the analysis in section 3 , it is easy to see that the value of $e=e_{F}+e_{S}$ is a concave function of $\alpha$. For sufficiently high values of $c_{F}^{\prime}$ (and/or sufficiently low values of $c_{S}^{\prime}$ ), $e$ is increasing throughout the range $\alpha \in\left[0, u_{S}^{P}\right]$, and for sufficiently low values of $c_{F}^{\prime}$ (and/or sufficiently high values of $c_{S}^{\prime}$ ), $e$ is decreasing throughout the range $\alpha \in\left[0, u_{S}^{P}\right]$. But for intermediate values of $c_{F}^{\prime}$ and $c_{S}^{\prime}$, e has an interior maximum with $\alpha \in\left[0, u_{S}^{P}\right]$. At low levels of patent protection (implying a low value of $\alpha$ ), increasing patent protection increases licensing rates. However, at high levels of patent protection 
(implying a high value of $\alpha$ ), increasing patent protection decreases licensing rates. Lerner (2002) provides evidence that suggests a similar inverse-U relationship between patent protection and patenting rates.

\subsection{Complementary search process}

So far we assumed that the matching process consists of independent searches. We briefly consider an alternative model where it is impossible to find a firm, unless it makes an effort to be found - and similarly for a scientist. One can think of a variety of model specification here, but we focus on a simple of model "double coincidence," where a match can occur only if both parties make an effort. A simple example would be if firms and scientist have to rely on meeting each other in a common location (such as a conference). The instantaneous probability of a match is now given by $e=e_{S} * e_{F}$. Straightforward calculations show that the steady state first order conditions are given by

$$
n_{F} e_{F}\left(u_{S}-U_{S}\right)-c_{S}^{\prime}=0 \text { and } n_{S} e_{S} u_{F}-c_{F}^{\prime}=0 .
$$

Using similar reasoning as before, this can be rewritten as

$$
n_{F} e_{F} \frac{(r+\delta) u_{S}+c_{S}}{r+\delta+n_{F} e_{S} e_{F}}-c_{S}^{\prime}=0 \text { and } e_{S} \frac{s u_{F}}{\delta+n_{F} e_{F} e_{S}}-c_{F}^{\prime}=0
$$

An interesting result is that the steady state reaction functions are no longer substitutes, but complements. ${ }^{23}$ This implies there may be multiple equilibria. ${ }^{24}$ Indeed, the above equations reveal that there always exists an equilibrium where $e_{S}=e_{F}=0$. That is, there always exists an equilibrium where the market collapses, because each side of the market is waiting for the other to make itself visible. Scientists do not invest in search, because firms are impossible to find, and vice versa. In addition to this coordination failure equilibrium, there may exist one or several equilibria where

\footnotetext{
${ }^{23}$ To see this, simply note that the scientists' marginal benefit can be rewritten as $n_{F} \frac{(r+\delta) u_{S}+c_{S}}{\underline{r+\delta}+n_{F} e_{S}}$, which is increasing in $e_{F}$. Similarly, the firms' marginal benefit can be rewritten as $\frac{e_{F}}{\frac{\delta}{e_{S}}+n_{F} e_{F}}$, which is increasing in $e_{S}$.

${ }^{24}$ Milgrom and Shannon (1994) provide a very general theorem of how complementarities in reaction functions can generate multiple equilibria.
} 
both parties do invest in search (i.e., $\left.e_{S}, e_{F}>0\right)$.

\section{Conclusion}

In this paper we examine an ex-post rationale for the patenting of scientific discoveries. At the core of the model is the problem that scientists rarely know what industrial applications may exist for their scientific discoveries. At the same time firms are often unaware what scientific discoveries might help them with their needs. We call this the science to market gap. The gap can be bridged when scientists and firms engage in a process of search and communication. Since patenting affects the distribution of rents,

it has an effect on the relative search intensities of firms and scientists. Patenting scientific discoveries bolsters the scientific community to "push" their discoveries out to industry. However, it may also dampen firms' incentives to "pull" discoveries out of academia. The net effect of patenting depends on the relative ease of bridging the science to market gap through "push" or "pull."

The model also examines the importance of universities' technology transfer offices. In principle such offices allow for task specialization. Scientist benefit from delegating search activities, which may free them up to pursue further research. However, the model explains that such delegation typically requires patenting. This argument generates a separate rationale for the patenting of scientific discoveries.

As with any economic theory, our model has some restrictive assumptions, and reality is always more complex. This leaves the door open for future research. For instance, our analysis is focussed on the use of scientific discoveries for developing new industrial applications. It ignores the use of scientific discoveries for subsequent scientific work. Murray and Stern (2005) provide evidence that patenting of scientific discoveries may have a negative impact on further scientific progress. Future research could examine the desirability of patenting when scientific discoveries have multiple uses. 


\section{References}

1. Aghion, Philippe, Mathias Dewatripont and Jeremy Stein, 2005 "Academia, the private sector, and the process of innovation" Mimeo, Harvard University

2. Arora, Ashish, 1995, "Licensing Tacit Knowledge: Intellectual Property Rights and the Market for Know-How" Economics, Innovation, New Technology, 4, 41-59

3. Arora, Ashish, 1996, "Contracting for Tacit Knowledge: The Provision of Technical Services in Technology Licensing" Journal of Development Economics, 50, August, 233-256

4. Arora, Ashish, Marco Ceccagnoli and Wesley Cohen, 2003, "R\&D and the Patent Premium" NBER Working Paper 9431

5. Azoulay, Pierre, Ding, Waverly, and Stuart, Toby, 2005, "The Effect of Academic Patenting on (Public) Research Output" Mimeo, Columbia University

6. Binmore Ken, Ariel Rubinstein and Asher Wolinsky, 1986, "The Nash bargaining solution in economic modelling." Rand Journal of Economics, Summer, $17(2), 176-188$.

7. Carmichael, H. Lorne, 1988, "Incentives in Academics: Why Is There Tenure?" Journal of Political Economy 96: 453-72

8. Cohen, Wesley, and Dan Levinthal, 1989, "Innovation and Learning: the two faces of R\&D" Economic Journal, 99, 569-596

9. Cohen, Wesley, and Dan Levinthal, 1990, "Absorptive capacity: a new perspective on learning and innovation" Administrative Quarterly Journal, 35, 128-152

10. Cohen, Wesley, A. Nagata, Richard Nelson and J. Walsh, 2002, "R\&D Spillovers, Patents, and the Incentive to Innovate in Japan and the United States" Research Policy, 31, 1349-1367

11. Denicolò, Vincenzo, and Luigi Franzoni, 2004, "The contract theory of patents" International Review of Law and Economics, 23, 365-380 
12. Elfenbein, Daniel, 2005, "Marketing University Inventions: The Role of Property Rights, Publications, and Patent Quality" Paper presented at the NBER conference on Academic Science \& Entrepreneurship

13. Gallini, Nancy, 2002, "The Economics of Patents: Lessons from Recent US Patent Reform" Journal of Economic Perspectives, 16, 2, Spring, 131-154

14. Gallini, Nancy, and Susan Scotchmer, 2001, "Intellectual Property: When is it the best incentive system?" in Innovation Policy and the Economy, vol. 2, chapter 2, Adam Jaffee, Josh Lerner and Scott Stern, eds., MIT Press, Boston, Massachusetts.

15. Green, Jerry, and Susan Scotchmer, 1995, "On the division of profit in sequential innovation" Rand Journal of Economics, 26,1, 20-33

16. Hart, Sergiu, and Andreu Mas-Collel, 1986, "Bargaining and Value" Econometrica, $64,2,357-380$

17. Hellmann, Thomas and Enrico Perotti, 2005, "The Circulation of Ideas: Firms versus Markets" Mimeo, University of British Columbia

18. Henderson, Rebecca, Adam Jaffee and Manuel Trajtenberg, 1998, "Universities as a source of commercial technology: a detailed analysis of university patenting, 1965-1988" The Review of Economics and Statistics, 119-127

19. Hoppe, Heidrum, and Emre Ozdenoren, 2005, "Intermediation in Innovation" Mimeo, University of Bonn

20. Jaffe, Adam, 2000, "The US Patent system in Transition: Policy Innovation and the Innovation Process" Research Policy, 29, 4-5, 531-557

21. Jaffe, Adam, Josh Lerner, 2001, "Reinventing Public R\&D: Patent Law and Technology Transfer from Federal Laboratories" Rand Journal of Economics, 32, Spring, 167-198

22. Jensen, Richard and Marie Thursby, 2001, "Proofs and Prototypes for Sale: The Licensing of University Inventions" American Economic Review, 91, 1, 240-259

23. Kitch, Ed, 1977, "The Nature and Functions of the Patent System" The Journal of Law and Economics, 265-290 
24. Lamoreaux, Naomi, and Kenneth Sokoloff, 1999, "Incentive Activity and the market for technology in the United States, 1840-1920" NBER Working Paper 7107, May

25. Lamoreaux, Naomi, and Kenneth Sokoloff, 2001, "Market Trade in Patents and the Rise of a Class of Specialized Inventors in the 19th Century United States" American Economic Review, Papers and Proceedings, 91, 2, May, 39-44

26. Lerner, Joshua, 2002, "150 Years of Patent Protection," American Economic Review, Papers and Proceedings, 92, May, 221-225

27. Levin, Richard, Alvin K. Kelvorick, Richard R. Nelson and Sidney G. Winter, 1987, "Appropriating the Returns from Industrial R\&D," Brooking Papers on Economic Activity, 3, 785-832

28. Merges, Robert, and Richard Nelson, 1990, "On the complex economics of patent scope" Columbia Law Review, 90, 839-916

29. Merges, Robert, and Richard Nelson, 1994, "On limiting or encouraging rivalry in technical progress: the effect of patent scope decisions" Journal of Economic Behavior, 25, 1-24

30. Milgrom, Paul, and Chris Shannon, 1994, "Monotone Comparative Statics" Econometrica, 62, 157-180.

31. Murdock, Kevin, 2002, "Intrinsic Motivation and Optimal Incentive Contracts" Rand Journal of Economics, 33, 4, 650-671

32. Murray, Fiona, and Scott Stern, 2005 "Do Formal Intellectual Property Rights Hinder the Free Flow of Scientific Knowledge? Evidence from Patent-Paper Pairs" Paper presented at the NBER conference on Academic Science \& Entrepreneurship

33. Scotchmer, Susan, 1991, "Standing on the Shoulders of Giants: Cumulative Research and the Patent Law" Journal of Economic Perspectives, 5,1, 29-41

34. Shane, Scott, 2004a, "Encouraging university entrepreneurship? The effect of the Bayh-Dole Act on university patenting in the United States" Journal of Business Venturing, 19, 127-151 
35. Shane, Scott, 2004b, Academic Entrepreneurship: University Spinoffs and Wealth Creation, New Horizons in Entrepreneurship, Edward Elgar, Northampton, Massachusetts, US

36. Stern, Scott, 2004, "Do Scientists Pay to Be Scientists?" Management Science, June, 50, 6, 835-854

37. Thursby, Jerry, Marie Thursby, and Swastika Mukherjee, 2005, "Are there real effects of licensing on academic research" Mimeo, Georgia Institute of Technology 


\section{Appendix}

\section{Proof of Proposition 1:}

Let $\theta_{S}=u_{S}-U_{S}$. The second order condition requires $-n_{F} \frac{d \theta_{S}}{d e_{S}}-c_{S}^{\prime \prime}<0$. Using (2) we get $\theta_{S}=u_{S}-\frac{n_{F} e_{S} u_{S}-c_{S}}{r+\delta+n_{F} e_{S}}$. It is useful to also rewrite this as $\theta_{S}=\frac{(r+\delta) u_{S}+c_{S}}{r+\delta+n_{F} e_{S}}$, so that $\frac{d \theta_{S}}{d e_{S}}=\frac{\left(r+\delta+n_{F} e_{S}\right) c_{S}^{\prime}-\left((r+\delta) u_{S}+c_{S}\right) n_{F}}{\left(r+\delta+n_{F} e_{S}\right)^{2}}$. Using the first order condition (7), we note that $\frac{d \theta_{S}}{d e_{S}}=\frac{n_{F}\left[\left((r+\delta) u_{S}+c_{S}\right)-\left((r+\delta) u_{S}+c_{S}\right)\right]}{\left(r+\delta+n_{F} e_{S}\right)^{2}}=0$. Thus convexity of $c_{S}$ guarantees that the second order condition is always satisfied.

The effect of patenting is to increase $u_{S}$. We have $\frac{d \theta_{S}}{d u_{S}}=1-\frac{n_{F} e_{S}}{r+\delta+n_{F} e_{S}}=$ $\frac{r+\delta}{r+\delta+n_{F} e_{S}}>0$, so that $\frac{d e_{S}}{d u_{S}}=\frac{-1}{c_{S}^{\prime \prime}} n_{F} \frac{d \theta_{S}}{d u_{S}}>0$.

\section{Proof of Proposition 2:}

We use $u_{S}=\alpha$ and $u_{F}=\pi-\alpha$. We represent stronger intellectual property protection as an increase in $\alpha$. We totally differentiate the two equations in (9) with respect to $\alpha$, and obtain $\left(\begin{array}{ll}x_{11} & x_{12} \\ x_{21} & x_{22}\end{array}\right)\left(\begin{array}{c}d e_{S} \\ d e_{F}\end{array}\right)+\left(\begin{array}{l}y_{1} \\ y_{2}\end{array}\right) d \alpha=0$, where $x_{11}=-c_{S}^{\prime \prime}<$ $0,{ }^{25} x_{12}=-n_{F} \frac{n_{F}\left(r \alpha+\delta \alpha+c_{S}\right)}{\left(r+\delta+n_{F} e_{F}+n_{F} e_{S}\right)^{2}}<0, x_{21}=-n_{F} \frac{s(\pi-\alpha)}{\left(\delta+n_{F} e_{F}+n_{F} e_{S}\right)^{2}}<0$, $x_{22}=-\frac{n_{F} s(\pi-\alpha)}{\left(\delta+n_{F} e_{F}+n_{F} e_{S}\right)^{2}}-c_{F}^{\prime \prime}<0, y_{1}=\frac{n_{F}(r+\delta)}{r+\delta+n_{F} e_{F}+n_{F} e_{S}}>0$, and $y_{2}=$ $-\frac{s}{\delta+n_{F} e_{F}+n_{F} e_{S}}<0$. Thus $\left(\begin{array}{c}d e_{S} \\ d e_{F}\end{array}\right)=\frac{-1}{x_{11} x_{22}-x_{12} x_{21}}\left(\begin{array}{cc}x_{22} & -x_{12} \\ -x_{21} & x_{11}\end{array}\right)\left(\begin{array}{l}y_{1} \\ y_{2}\end{array}\right) d \alpha$.

The condition $\frac{-1}{x_{11} x_{22}-x_{12} x_{21}}<0$ ensures that the equilibrium is stable. Thus $\frac{d e_{S}}{d \alpha}=-\frac{x_{22} y_{1}-x_{12} y_{2}}{x_{11} x_{22}-x_{12} x_{21}}>0$ and $\frac{d e_{F}}{d \alpha}=-\frac{x_{11} y_{2}-x_{21} y_{1}}{x_{11} x_{22}-x_{12} x_{21}}<0$. In addition, note that $\frac{d\left(e_{S}+e_{F}\right)}{d \alpha}=\frac{\left(x_{21}-x_{22}\right) y_{1}+\left(x_{12}-x_{11}\right) y_{2}}{x_{11} x_{22}-x_{12} x_{21}}$. We note that this is increasing in $x_{11}$, and thus decreasing in $c_{S}^{\prime \prime}$. Hence, if scientists have sufficiently steep marginal costs, then an increase in intellectual property rights increases $e_{S}$ by less than it decreases $e_{F}$.

\section{Proof of Proposition 4:}

\footnotetext{
${ }^{25}$ To see that $x_{11}$ reduces to $x_{11}=-c_{S}^{\prime \prime}$, we totally differentiate the first equation w.r.t. $e_{S}$ and obtain $\frac{n_{F} c_{S}^{\prime}\left(r+\delta+n_{F} e_{F}+n_{F} e_{S}\right)-n_{F}\left(r \alpha+\delta \alpha+c_{S}\right) n_{F}}{\left(r+\delta+n_{F} e_{F}+n_{F} e_{S}\right)^{2}}-c_{S}^{\prime \prime}$. We then use the first condition again, which can be rewritten as $c_{S}^{\prime}\left(r+\delta+n_{F} e_{F}+n_{F} e_{S}\right)=n_{F}\left(r \alpha+\delta \alpha+c_{S}\right)$. Thus $x_{11}=-c_{S}^{\prime \prime}$.
} 
The optimal ex-ante contract maximizes $\widetilde{U}_{S}+\widetilde{U}_{T}$. For $c_{S}^{\prime}>c_{T}^{\prime}$, it is always more efficient that the TTO incurs the search costs. Straightforward calculations reveal that the jointly optimal search effort is now given by the following variant of equation (7): $n_{F}\left(u_{S}+u_{T}-U_{S}\left(\tau_{1}\right)-U_{T}\left(\tau_{1}\right)\right)-c_{T}^{\prime}=0$. Naturally, the TTO continues to optimize privately, so that $e_{T}$ satisfies $n_{F}\left(\widetilde{u}_{T}-U_{T}\left(\tau_{1}\right)\right)-c_{T}^{\prime}=0 .{ }^{26}$ The optimal $\tau_{1}$ needs to satisfy $\widetilde{u}_{T}-U_{T}\left(\tau_{1}\right)=u_{S}+u_{T}-U_{S}\left(\tau_{1}\right)-U_{T}\left(\tau_{1}\right) \Leftrightarrow \tau_{1}=u_{S}-U_{S}\left(\tau_{1}\right)$. This is always satisfied for $\tau_{1}^{*}=u_{S}$, since $\tau_{1}^{*}=u_{S} \Leftrightarrow \widetilde{u}_{S}=0 \Leftrightarrow U_{S}\left(\tau_{1}^{*}\right)=0$.

To see that $\tau_{0}<0$, we simply consider the ex-ante Nash bargaining game between the scientist and the TTO. In case of disagreement, we assume that the two parties simply proceed without a contract. In this case, the model reverts back to the incomplete contracts setting. Thus, $\widetilde{U}_{S}=\frac{U_{S}\left(\tau_{1}^{*}\right)+U_{T}\left(\tau_{1}^{*}\right)+U_{S}-U_{T}}{2}$ and $\widetilde{U}_{T}=\frac{U_{S}\left(\tau_{1}^{*}\right)+U_{T}\left(\tau_{1}^{*}\right)-U_{S}+U_{T}}{2}$. Using $\widetilde{U}_{S}=U_{S}\left(\tau_{1}^{*}\right)-\tau_{0}$ and $U_{S}\left(\tau_{1}^{*}\right)=0$, we obtain $\tau_{0}^{*}=-\frac{U_{T}\left(\tau_{1}^{*}\right)-U_{T}+U_{S}}{2}<0$.

\section{Analysis of the model with $\tau_{0} \geq 0$}

We briefly sketch the model where the scientist can provide incentives to the TTO. The scientist maximizes $U_{S}\left(\tau_{1}\right)=\frac{m_{T}\left(u_{S}-\tau_{1}\right)}{r+\delta+m_{T}}$, subject to the first-order condition of $e_{T}(t)$, given by $n_{F}\left[u_{T}(t)+\tau_{1}-\frac{1-\delta \Delta}{1+r \Delta} U_{T}\left(\tau_{1}, t+\Delta\right)\right]-c_{T}^{\prime}(t)=0$. We note that $\frac{d U_{S}\left(\tau_{1}\right)}{d \tau_{1}}=\frac{\left(u_{S}-\tau_{1}\right)(r+\delta)}{\left(r+\delta+m_{T}\right)^{2}} \frac{d m_{T}}{d \tau_{1}}-\frac{m_{T}}{r+\delta+m_{T}}$, where the first term captures the benefit of increasing incentives, and the second term captures the cost of providing incentives. To evaluate the incentive effect we use $U_{T}\left(\tau_{1}\right)=\frac{m_{T}\left(u_{T}+\tau_{1}\right)-c_{T}}{r+\delta+m_{T}}$ and totally differentiate the first order condition. For $\Delta \rightarrow 0$ we have $n_{F}\left[1-\frac{m_{T}}{r+\delta+m_{T}}\right] d \tau_{1}-$ $c_{T}^{\prime \prime} d e_{T}(t)=0 \Leftrightarrow \frac{d e_{T}}{d \tau_{1}}=\frac{n_{F}}{c_{T}^{\prime \prime}} \frac{(r+\delta)}{r+\delta+m_{T}}$. Using $\frac{d m_{T}}{d \tau_{1}}=n_{F} \frac{d e_{T}}{d \tau_{1}}$ we finally obtain $\frac{d U_{S}}{d \tau_{1}}=\frac{\left(n_{F}\right)^{2}(r+\delta)^{2}}{\left(r+\delta+m_{T}\right)^{3}} \frac{\left(u_{S}-\tau_{1}\right)}{c_{T}^{\prime \prime}}-\frac{m_{T}}{r+\delta+m_{T}}$. The constrained optimal $\tau_{1}$ is positive whenever $\frac{d U_{S}}{d \tau_{1}}>0$ at $\tau_{1}=0$. We obtain three results. First, higher values of $u_{S}$ increase $\frac{d U_{S}}{d \tau_{1}}$, meaning that the scientist has a stronger desire to voluntarily provide incentives. Second, higher values of $c_{T}^{\prime \prime}$ decrease $\frac{d U_{S}}{d \tau_{1}}$, showing that the scientist is

\footnotetext{
${ }^{26}$ Note that the ex-ante transfer $\tau_{0}$ does not influence this equation, hence the use of $U_{T}\left(\tau_{1}\right)$, rather than $\widetilde{U}_{T}\left(\tau_{1}\right)$.
} 
less interested in providing incentives when the TTO's search behavior is inelastic. Third, even if the scientist provides incentives, the constrained optimal $\tau_{1}$ always lies below the unconstrained optimal $\tau_{1}^{*}=u_{S}$. At $\tau_{1}^{*}$, the first term is zero, indicating that the marginal benefit of providing benefit is zero, while the marginal cost remains positive. 